\title{
THE METHOD FOR SETTING MAP SHEET IDENTIFICATION NUMBERS IN THE INTERNATIONAL MAP OF THE WORLD (IMW) SYSTEM
}

\author{
Mariusz Zygmunt, Jacek Gniadek, Robert Szewczyk
}

\begin{abstract}
Summary
The systematic division into section sheets adopted in the International World Map is the standard in many countries. This division is used for most types of small-scale maps. Due to the scope of application, it is also often the basis for indexing orthophoto images and data from laser scanning. Data accumulated in central State resources cover entire countries. Their coverage includes more than information obtained and processed for the users' needs in the source format. Increasingly often, data is transformed into formats that facilitate their application (e.g. setting up a GRID for a digital terrain model). The need for quick spatial identification is a determinant of the availability of resources stored in these databases. The dynamic development of Open Source software in the fields of GIS is another increasingly broad area of study, and the research focus of scientists from around the world. They see it not only as a ready-made tool for conducting spatial analyses, but also in terms of searching for algorithmic solutions to meet the needs resulting from the requirement to process ever larger amounts of this type of data. The present paper discusses the method for designating a map sheet identification number (index) in a selected scale, based on the longitude and latitude of the given point. An unquestionable advantage of the presented solution is the possibility of dividing map sheets into scales, which were missing in their basic description. It follows from the fact that this spatial indexing method is indispensable for large amounts of data.
\end{abstract}

\section{Keywords}

IMW • index map • geometrical geodesy • Open Source

\section{Introduction}

The systematization of the reality that surrounds us lies at the basis of the idea of creating maps for the entire globe. The first originator thereof was the German geographer Albrecht Penck (1858-1945). In 1891, at an international geographic conference, he proposed dividing the globe into 2,500 sheets of maps at a scale of 1:1,000,000. Each map was to cover an area of six degrees longitude and four degrees latitude [http:// maps.bpl.org/id/m8799]. Although his project has not been implemented in full, 
assumptions as to the method of division into sectional sheets are used in many countries around the world [Parry and Perkins 2002]. In a changed form, the concept is still extant today, functioning under the name of Mapping Project Global (GMP) [Pearson et al. 2006]. Many contemporary maps are also based on the IMW grid - take the World Aeronautical Chart (WAC) [http://www.icsm.gov.au/mapping/maps_topographic. html] for example. In a computer, the transformation from the world around us to its representation is carried out using a data model [Bielecka 2006]. Access to the data is one of the basic issues [Gaździcki 1990]. The presented solution concerns research on the automation of this process, falling under the section of algorithmics that deals with computational geometry [Banachowski et al. 1999, Cormen et al. 2004].

[ㄴ]

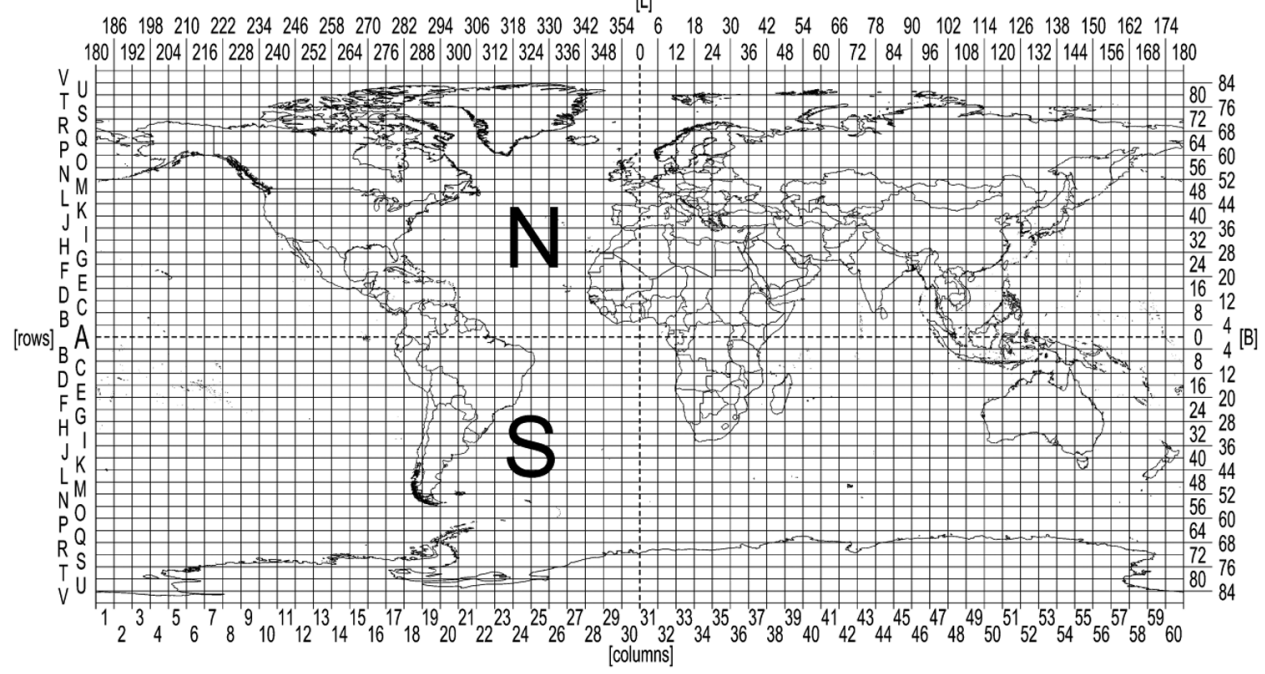

Source: Authors' own study

Fig. 1. Illustrative division of the world map into sheets in the scale of $1: 1,000,000$

\section{Manner of dividing the map into sheets for various scales}

The size of the base sheet in the scale of 1:1,000,000 covers an area of six degrees longitude and four degrees latitude. The sheets are numbered with Arabic numerals from 1 to 60 relative to their longitude, forming columns. The starting point is the Greenwich $180^{\text {th }}$ meridian (or the antimeridian). The lines are numbered from the equator with alphabet letters from A to Z. To separate the northern and southern hemispheres, the letter identifying the relevant hemisphere is used as a distinguishing feature, $\mathrm{N}$ or $\mathrm{S}$ respectively. For a scale of 1:1,000,000, an example of the map sheet identification numbers might take the form: N-M-34 for the northern hemisphere, or S-B-35 for the southern hemisphere. In the case of maps showing areas located only in one of the hemispheres, the 
identification of N/S is mostly omitted. The sheet's division in the scale of 1:1,000,000 can be conducted according to several patterns. In order to obtain a sheet in the scale of 1:500,000, we divide the map sheet into 4 parts, marking the resulting sheets with successive letters A, B, C, and D. In order to obtain a sheet in the scale of 1:200,000, we divide it into 36 sheets, marking them with subsequent Roman numerals. A map sheet in the scale of $1: 100,000$ is produced by dividing a sheet in the $1: 1,000,000$ scale into 144 sheets numbered with Arabic numerals 1-144 (Fig. 2). Map sheet identification numbers for the 1:500,000, 1:200,000 and 1:100,000 scales are created by adding the appropriate designation to the map sheet ID numbers in the 1:1,000,000 scale, e.g. NM-34-111 for the 1:100,000, NM-34-XXX scale for the scale of 1:200,000 (Fig. 2).

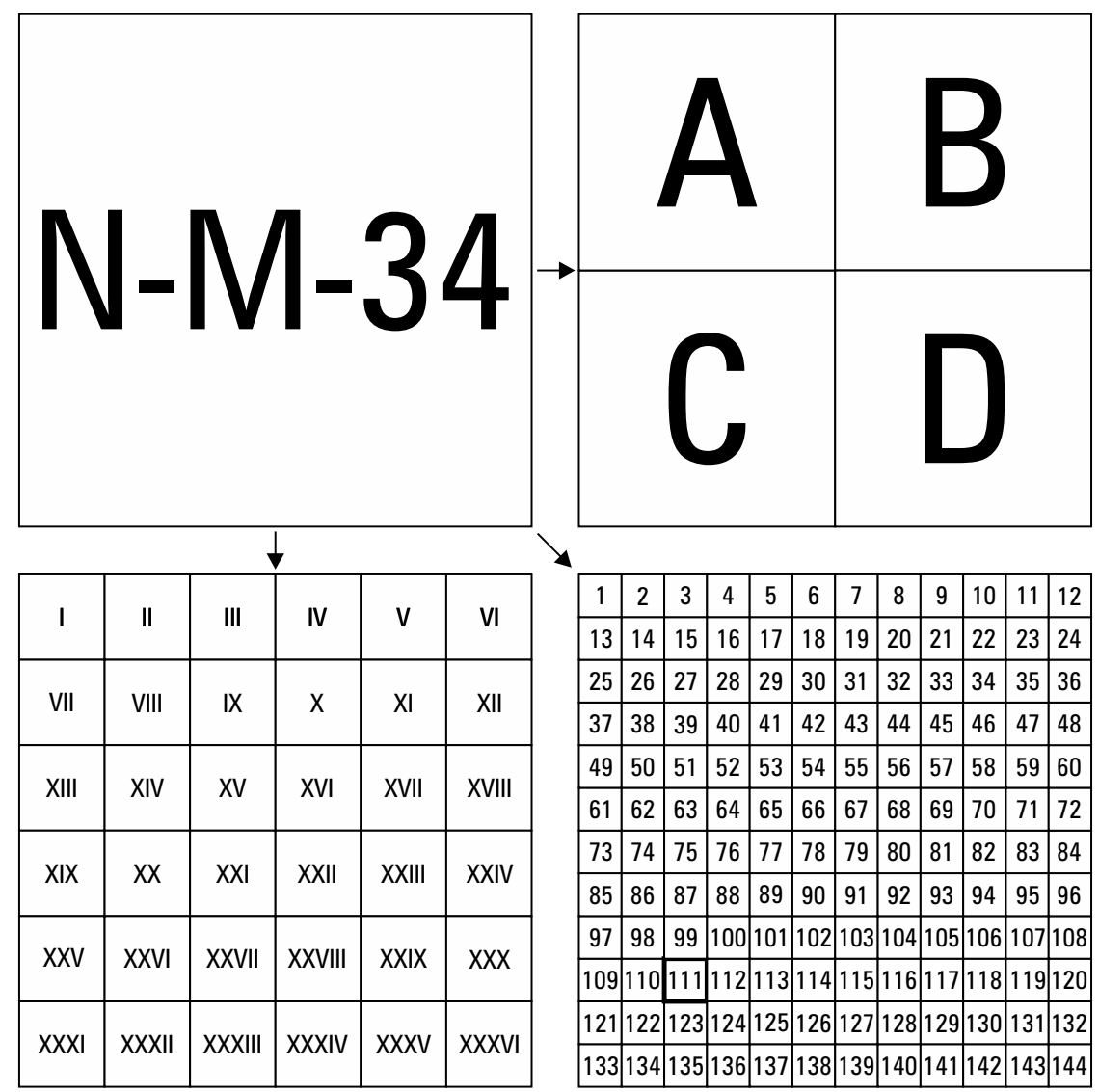

Source: Authors' own study

Fig. 2. Manner of dividing the N-M-34 basic sheet in the scale of 1:1,000,000

Division into larger scales is made by dividing the sheet in the scale of 1:100,000 into 4 parts in the scale of 1:50,000 marked with the letters A, B, C, and D. Subsequently, 
each of the sheets is divided into 4 parts in the scale of 1:25,000 marked with the letters $\mathrm{a}, \mathrm{b}, \mathrm{c}$, and $\mathrm{d}$. A sheet in the scale of 1:10,000 is created by dividing the sheet in the scale of 1:25,000 again into 4 parts marked with consecutive numbers 1,2, 3, and 4 .

The map sheet identification number in this scale looks as follows: NM-34-111-Ca-3 (Fig. 3).

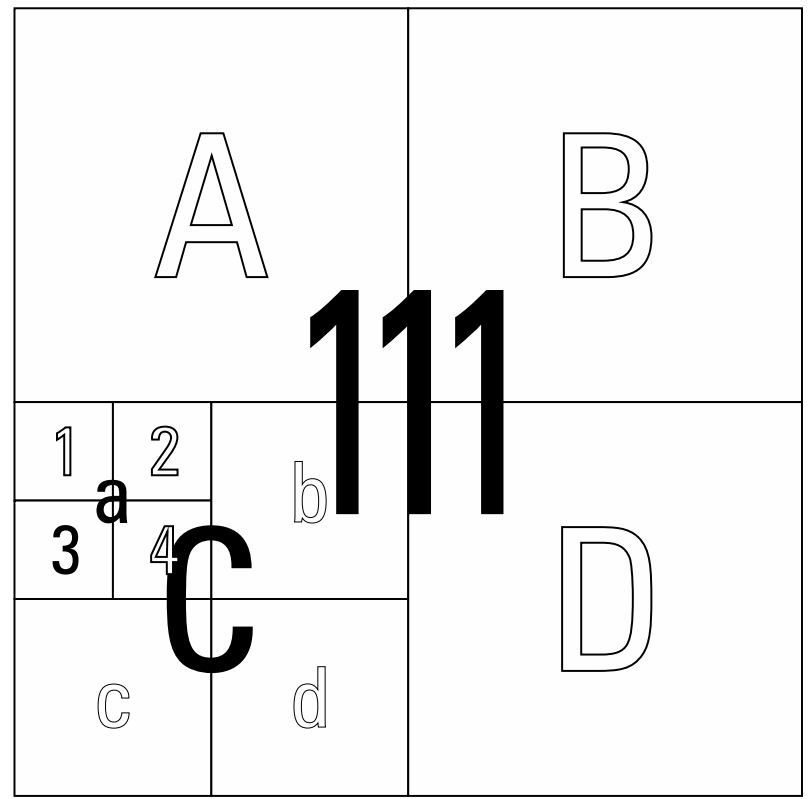

Source: Authors' own study

Fig. 3. Manner of dividing sheet No. 111 in the scale of 1:100,000

\section{Algorithm description}

The description of the algorithm is illustrated with the example of the code written in the BASIC programming language. The decision was made to do so rather than use pseudocode for practical reasons. Currently, most CAD-GIS systems and computational software programs implement Visual Basic for Applications. The simplest data structures were used in order to facilitate code portability. Latitude and longitude are displayed in tenths of a degree.

Calculating map sheet identification number based on point coordinates

Listing Algorithm: Get_INDEX_IMW

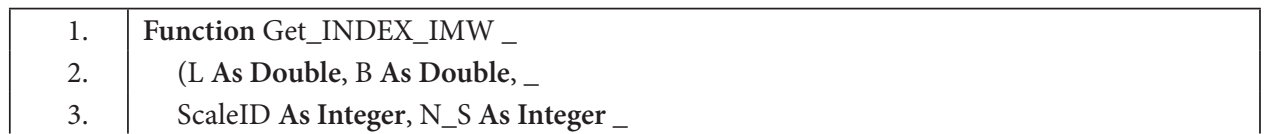




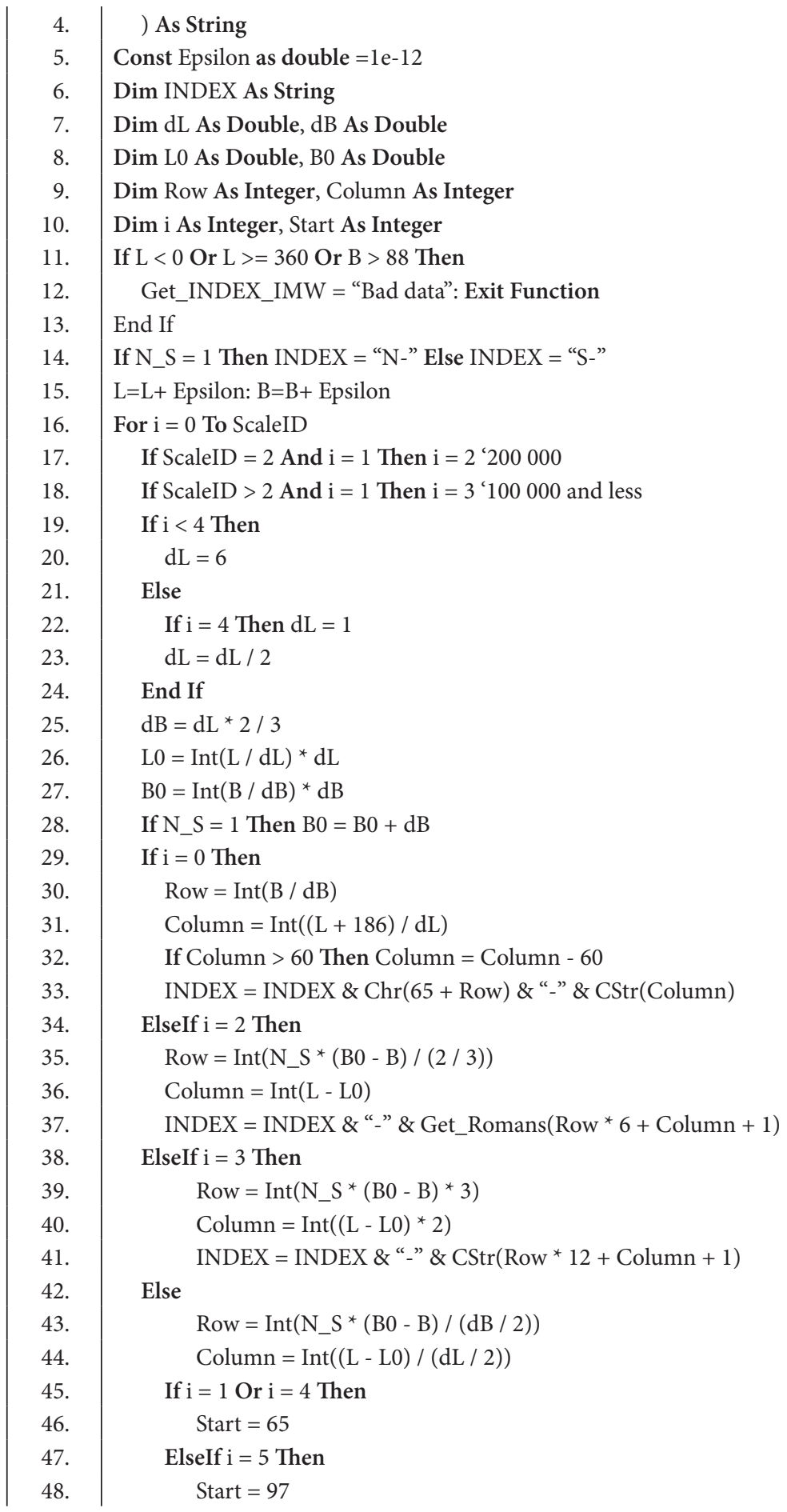




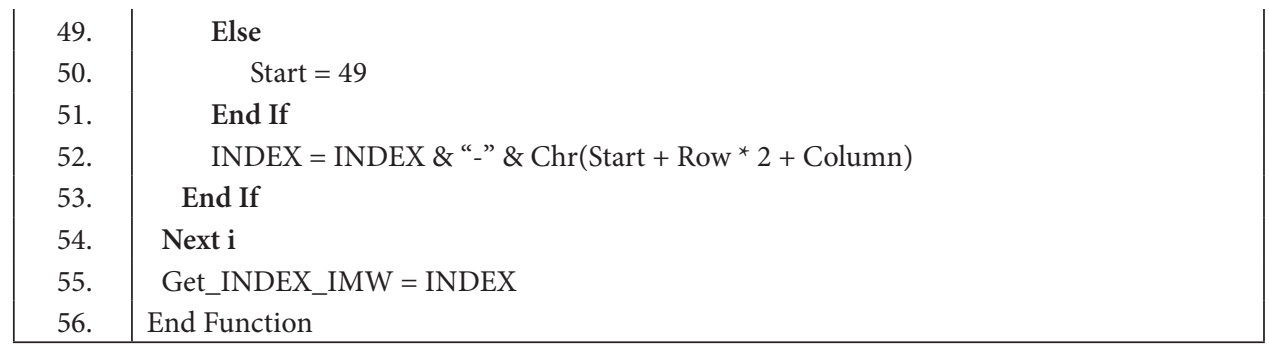

Line 1 contains the name of the function. In lines 2 and 3, the input arguments necessary for the algorithm to work are defined. In line 5, the constant Epsilon is declared. From lines 6 to 10 there follows the local variable declaration section. In lines $11-15$, the correctness of the input data is tested, and the initial algorithm substitutions are made. From lines 16 to 54, the most important computational part is performed. Line 55 introduces the final score.

\section{Detailed description of the algorithm Get_INDEX_IMW}

Line 2: Defines the input fields, Longitude L, and Latitude B. These data must be provided in degrees, in decimal measure.

Line 3: Defines the ScaleID and N_S variables.

The ScaleID variable is responsible for the scale for which the map sheet identification number (index) is generated.

The acceptable values remain in the range $0-6$, and they correspond to the following scales, respectively:

$0-1: 1,000,000$

$1-1: 500,000$

$2-1: 200,000$

$3-1: 100,000$

$4-1: 50,000$

$5-1: 25,000$

$6-1: 10,000$

The algorithm also takes into account an alternative, further division of the sheet in the scale of 1:10,000 into smaller sheets in the order of 1-4.

The ScaleID value can then be 7, 8, etc. For ScaleID $=7$, the exemplary map sheet identification numbers will have the designation N-M-34-111-C-a-3-1. This type of marking can be found during the identification of orthophoto images in the scale of 1:5,000. The variable S_N defines the hemisphere for which the calculations are to be performed. For the northern hemisphere, the variable N_S must take the value of 1, and for the southern hemisphere, -1 . 
Line 4: Definition of the value of the variable returned by the function, here:a string variable.

Line 5: Definition of the Epsilon constant. This is a very small value added to the $B, L$ coordinates. It does not affect the correctness of the calculations in any way. Its task is to unambiguously assign a map sheet identification number to the section frame in the case of the B or L coordinate overlapping with the section frame. In case of a positive value, the map sheet identification number will be calculated for the section for which the $\mathrm{B}$ and $\mathrm{L}$ values increase from the set point coinciding with the frame. The use of this constant also eliminates the need to consider special cases occurring at the section boundaries.

Line 6: Declaration of the INDEX variable to which the map sheet identification numbers identifier is assigned.

Line 7: Variable declaration: $\mathrm{dL}$ - frame range in relation to longitude, and $\mathrm{dB}$ - frame range in relation to latitude.

Line 8: Declaration of variables, for which the calculation of the left frame (L0), and the bottom frame (B0) will be performed.

Line 9: Declaration of the variable, for which the row and the column of the section frame will be calculated.

Line 10: Declaration of the algorithm loop counter and the Start variable defining the reading offset for the $\mathrm{Chr}$ function, describing the map sheet identification number components in individual scales.

Line 11-13: Conditional statement protecting the program from erroneous inputs B, L.

Line 14: Conditional statement defining the beginning of the map sheet identification number name, where the value of the INDEX variable depends on the northern or southern hemisphere.

Line 15: Addition of Epsilon values to the B, L coordinates.

Line 16: Start of the main algorithm loop.

Line 17: For scale 1:200,000, the loop counter jumps from $i=1$ to $i=2$ in order to skip the division to scale 1:500,000.

Line 18: For a scale of 1:100,000 and above, the loop counter jumps from $i=1$ to $i=3$ in order to skip the division of the sheet to a scale of $1: 500,000$ and $1: 200,000$.

Line 19: Conditional statement adopting for $i=0,1,2,3$ the range of the $\mathrm{dL}$ frame from line 20.

Line 21-22: For the remaining cases, the value for $i=4, \mathrm{dL}=1$ is assumed.

Line 23: The dL value for subsequent scales, for $i=5,6$ is the result of division into 2 .

Line 24: End of conditional statement.

Line 25: Calculation of the $\mathrm{dB}$ frame range. The value of $2 / 3$ results from the ratio of the sheet size.

Line 26: Calculation of the start of the section sheet relative to longitude. 
Line 27: Calculation of the beginning of the section sheet relative to latitude.

Line 28: Latitude correction of sheet origin for northern hemisphere.

Line 29: Conditional statement for $i=0$, which is a sheet in the scale of $1: 1,000,000$.

Line 30: Calculation of the section sheet row.

Line 31: Calculation of the section sheet column.

Line 32: Conditional statement that reduces the number of columns to the permissible value in the range $1-60$.

Line 33: Calculating the elements of the map sheet identification number, row and column for the scale of 1:1,000,000 and adding it to the INDEX variable.

Line 34: Conditional statement for the scale of 1:200,000.

Line 35, 36: Calculation of the row and column for a scale of 1:200,000 in a 1:1,000,000 frame layout.

Line 37: Calculating the map sheet identification number component for the scale of 1:200,000 and adding it to the INDEX variable. The Get_Romans function converts an Arabic number in the range of $1-36$ to a Roman number.

Line 38: Conditional statement for the scale of 1: 100,000 .

Line 39, 40: Calculation of the row and column for the scale of 1:100,000 in the $1: 1,000,000$ frame layout.

Line 41: Calculating the map sheet identification number component for the scale of $1: 100,000$ and adding it to the INDEX variable.

Line 42: Conditional statement for the scales of 1:500,000, 50,000, 25,000, 10,000.

Line 43, 44: Calculation of the row and the column in the frame layout for the given scale.

Line 45-51: Conditional statement that defines the start of the ASCII character shift, for determining the map sheet identification number components for a given scale.

Line 52: Calculating the map sheet identification number component for a given scale and adding it to the INDEX variable. This part of the algorithm is performed when the section frame is divided into 4 parts.

Line 53: End of compound conditional statement.

Line 54: End of main program loop.

Line 55: Assigning final value of the computed map sheet identification number to the Get_INDEX_IMW function.

Line 56: End of declaration of the function that calculates the map sheet identification number.

\section{Practical implementation}

The presented algorithm was used in the CAD graphics program in order to visualize the map sheet identification number in the 1992 system [Wytyczne Techniczne... 2001] (Fig. 4). In practice, it is a frame of reference based on plane XY coordinates. 
However, the division into section sheets, and thus their identification, is based on the MMS division and BL coordinates. The map sheet identification number symbol and the insertion point are directly related to the scale. The procedure is as follows:

1. Identification of the XY coordinate in the 1992 system.

2. Transformation of the XY coordinate from the 1992 system to the BL MMS system.

3. Determination of the map sheet identification number in the MMS system for the selected scale, using the algorithm.

4. Visualization of the MMS map sheet identification number in the XY 1992 system.

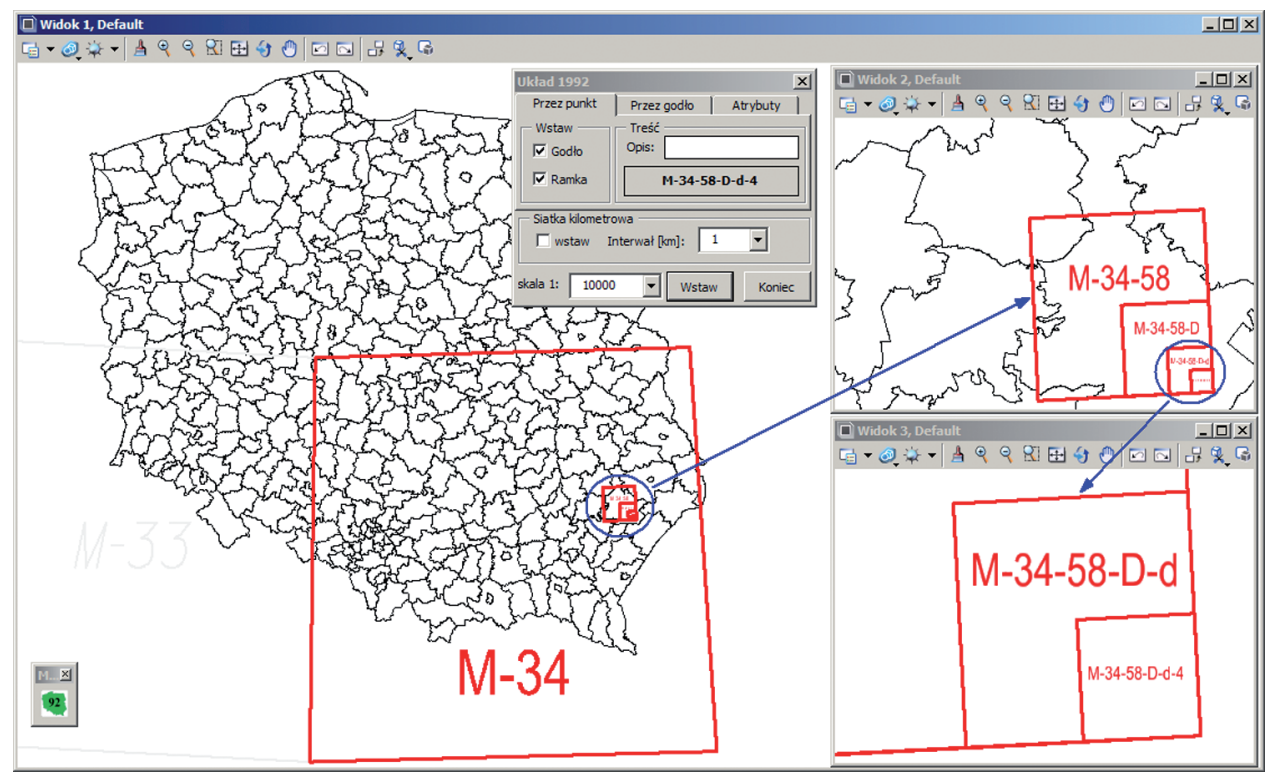

Source: Authors' own study

Fig. 4. Practical application of the algorithm. For illustrative purposes, section frame range for subsequent divisions of the selected scale was added.

\section{Discussion}

Globally, the division into sheets in the IMW presented in this paper is not the only one applicable. It may happen that for a particular scale the presented division scheme will be different. Obviously, this would require modifications of the algorithm and adapting it to a specific case.

The described procedure does not take into account the cases of areas located above the latitude of 60 degrees. Due to the mapping-resultant shortening, the horizontal range of the frame doubles to 12 degrees. Above 76 degrees, the range of the frame doubles to 24 degrees. For these cases, adjacent sheets are joined, and the map 
sheet identification number becomes a combination of the ID numbers of the joined sheets.

The Get_Romans function ensuring the correct handling of the map sheet identification number for the scale 1:200,000 can be replaced with a 36-element array of the string type. Subsequent elements of the array are assigned their Roman equivalents.

\section{Conclusions}

The paper presents a universal method for calculating the map sheet identification number for a point in the IMW system. The procedure allowed for a very quick assignment of point features to section sheets, without the need to analyse the geometric content of points in particular sections. We are dealing here with the concept of spatial indexing for the needs of GIS [Longley et al. 2006]. A reference to a spatial data set is made by quick computation and determining the range of spatial search. In this case, the limitations are determined by belonging to a map sheet with a known map sheet identification number. This method also enables very fast handling of reference files. In this case, the file name is the same as the map section in IMW. Loading the appropriate file is done by pointing the mouse cursor at the place on the map where the file is to be loaded. The use of the described algorithm also simplifies the work when handling raster images in the IMW system.

\section{References}

Banachowski L., Diks K., Rytter W. 1999. Algorytmy i struktury danych. WNT, Warszawa.

Bielecka E. 2006. Systemy informacji geograficznej. Teoria i zastosowania. Polsko-Japońska Wyższa Szkoła Technik Komputerowych. Warszawa.

Cormen T.H., Leiserson C.E., Rivest R.L., Stein C. 2004. Wprowadzenie do algorytmów. WNT, Warszawa.

Gaździcki J. 1990. Systemy Informacji Przestrzennej. PWN, Warszawa.

Longley P.A., Goodchild M.J., Rhind D.W. 2006. GIS. Teoria i praktyka. Wydawnictwo Naukowe PWN, Warszawa.

Parry R.B., Perkins C.R. 2002. World mapping today. Munchen, Saur.

Pearson A., Taylor D.R.F., Kline K.D., Heffernan M. 2006. Cartographic ideals and geopolitical realities: International maps of the world from the 1890s to the present. The Canadian Geographer, 50, 2, 149-176.

Wytyczne Techniczne G-1.10. 2001. Formuły odwzorowawcze i parametry układów współrzędnych. Główny Urząd Geodezji i Kartografii. Warszawa.

http://maps.bpl.org/id/m8799

http://www.icsm.gov.au/mapping/maps_topographic.html 
Mariusz Zygmunt

University of Agriculture in Krakow

Department of Land Surveying

ul. Balicka 253a, 30-149 Kraków

e-mail: mariusz.zygmunt@urk.edu.pl

ORCID: 0000-0003-0056-5215

Jacek Gniadek

University of Agriculture in Krakow

Department of Agricultural Land Surveying, Cadastre and Photogrammetry ul. Balicka 253a, 30-149 Kraków

e-mail: jacek.gniadek@urk.edu.pl

ORCID: 0000-0003-4381-5018

Robert Szewczyk

Department of Agricultural Land Surveying, Cadastre and Photogrammetry ul. Balicka 253a, 30-149 Kraków

e-mail: robert.szewczyk@urk.edu.pl

ORCID: 0000-0003-0885-8610 